\title{
Aproximación a un Balance sobre Campesinado y Descampesinización en el Perú
}

Roxana Barrantes Cáceres

\section{Introducción.}

DESDE QUE MARX, Kautsky y Lenin plantearon las peculiaridades que el proceso de desarrollo capitalista asumiera en algunos países de Europa principalmente Gran Bretaña y Rusia - han sido incontables el papel, la tinta $y$, fundamentalmente, las reflexiones dedicadas al tema.

Estos autores, a quienes podemos llamar clásicos, plantearon que el capitalismo, como modo de producción generado históricamente, es dinámico, englobante $\mathrm{y}$ destructor de los modos ( $\mathrm{y} / \mathrm{o}$ formas) de producción precedentes. Dentro de estos modos de producción que preceden al capitalismo podemos ubicar al campesinado, a los campesinos o lo que Marx llamaría "economía parcelaria". Siguiendo el argumento, el campesinado sería destruido por el desarrollo capitalista abriéndose para sus miembros dos alternativas: la proletarización urbana o rural y el aburguesamiento. A muy grandes rasgos es así como sucedió en gran parte de Europa.

Cuando se intenta la explicación de estos fenómenos en países de capitalismo sub-determinado 1 (Rochabrún 1977), o bien de capitalismo importado como podrian ser considerados una buena parte de países del mundo. no necesariamente se llegan a análisis y conclusiones felices al usar este "modelo". ¿Cómo ha sido abordado este problema en el Perú? Precisamente el objetivo de estas notas es presentar las principales explicaciones que sobre el impacto de la expansión capitalista en las economías campesinas se han ofrecido en el Perú.

Para los clásicos, es el término descampesinización el usado para dar cuenta del fenómeno. ¿Es también descampesinización lo que se ha dado, 0 se está dando, en el Perú? ¿Qué posiciones son sostenidas? ¿Qué papel, y futuro, tienen las comunidades campesinas, necesarias protagonistas del proceso? Estas son algunas de las preguntas que pretendo dar respuesta. 
La preocupación por el tema y el abierto debate a que ha dado lugar son producto del boom de las ciencias sociales durante la década del $70 \mathrm{y}$ del especiàl interés que el agro suscitó hace ya algunos lustros. Esto se explica por la crisis del agro que se comenzó a sentir fuertemente desde la década del 50, y donde es el campesino, con sus movilizaciones, el principal impulsor de-esta preocupación (Iguiñiz: 1983). Los interesados coincidían en que el problema residia en la concentración de la propiedad de la tierra, la existencia de minifundios y el carácter tradicional de la clase terrateniente (Eguren: 1982). Es en gran parte en respuesta a esta problemática que el gobierno militar, en su primera fase $(68-75)$ promulga una ley de reforma agraria cuya aplicación sirve de contexto para las investigaciones sobre lo rural.

El específico problema al que se dedica este trabajo es además producto del veloz crecimiento de las ciudades y de uno de los factores al que está asociado: la migración del campo a la ciudad. Asimismo, las economías campesinas ofertan una parte de los alimentos consumidos en las ciudades ${ }^{2}$. Por otro lado, los grandes movimientos campesinos de las dos décadas anteriores dieron lugar a la constitución de la Confederación Campesina del Perú (CCP). La orientación maoísta de ella y de los partidos políticos a ella ligados genera que otorguen a campesinos y comunidades campesinas un papel fundamental en sus programas y proyectos. Desde esa óptica, su vigencia es un problema vital ${ }^{3}$.

La revisión bibliográfica se restringe al Centro de Documentación, Hemeroteca y Biblioteca de Ciencias Sociales de la Universidad Católica. Deliberadamente han sido omitidos algunos trabajos por su escasa calidad.

\section{Campesinos, campesinado y economía campesina ${ }^{4}$.}

Antes de intentar un balance sobre desarrollo del capitalismo y su impacto sobre el campesinado, es preciso presentar a los campesinos. Maletta (1978) resume dos principales vertientes para una conceptualización: la antropología económica (Wolf, Shanin) y la tradición marxista (Marx, Lenin). La primera propone al campesino como productor directo, de economía familiar y ubicado como un subgrupo dentro de una sociedad mayor que le extrae excedentes. La caracterización marxista, por su parte, es histórica: la propiedad y producción parcelarias tienen condiciones de surgimiento y disolución.

Para Aramburú (1979), las características del campesinado deben ser inscritas dentro del modo de producción mercantil simple, cuyos rasgos principales son el control directo de los medios de producción, economía familiar,
tecnología simple y nula capacidad de acumulación. En esto último coinciden Campaña y Rivera (1978), quienes agregan que los campesinos venden trabajo eventualmente; discrepan sin embargo en lo referido al ámbito de 
actividad: mientras que para Aramburú no se trata de qué hacen sino cómo lo hacen, para los segundos, los campesinos trabajan la tierra y sólo se dedican a actividades agropecuarias.

Para Sánchez (1979) el campesinado es un sector de clase parcialmente proletarizado y parcialmente marginalizado, definición imposible si no se la entiende en el marco de la economía capitalista, tal como es propuesto por el autor.

Sobre la economía campesina, una excelente presentación está constituida por el estudio de Adolfo Figueroa (1981), mostrando detalladamente las características de estas unidades de producción y consumo. Preceden a este trabajo Gonzales (1980) en su estudio de caso sobre Antapampa y Ma. Soledad de la Cadena (1980), sobre Yauyos. De ellos se deriva que las características más saltantes de las familias campesinas son las fuentes diversificadas de su ingreso - agricultura, ganadería, artesanias y venta de fuerza de trabajo- y su composición crecientemente monetaria. Esto remite necesariamente a la reafirmación del no aislamiento de la economía campesina respecto del "Perú oficial", hecho que puede visualizarse a través de las relaciones de intercambio mercantil.

Caracterizando a la economía campesina como economía de autosubsistencia, Gabriela Vega (1976) intenta una conceptualización desde la economía política. También Caballero (1983) afirma que a pesar de los cambios ocurridos la economía campesina se mantiene a nivel de reproducción simple.

\section{Comunidades campesinas.}

Estudios importantes afirman que el campesinado, y su estrategia de reproducción, no pueden aislarse del marco de la comunidad campesina. Quienes sostienen esta idea son principalmente Gonzales (1980). Monteagudo (1981) y Plaza (1981).

Henry Dobyns (1972) es uno de los primeros en ordenar las características de estas comunidades, aunque con una limitación: su información fue recogida entre comunidades reconocidas oficialmente que respondieron un cuestionario enviado por correo. Ya en este trabajo se presentan evidencias del no aislamiento de. las comunidades. Posteriormente Sinamos, Cencira y el Ministerio de Agricultura son instituciones que presentan documentos sobre caracteristicas globales de las comunidades.

La comunidad ha sido objeto de idealización como institución igualitarista donde los ideales de reciprocidad y redistribución propios de la zona andina están todavia vigentes. Frente a esta apreciación, la mayoría de autores ya coincide en los cambios que sufre la comunidad por efecto de la penetración mercantil. Mayer y Alberti (1974) afirman que esta afecta la reciprocidad atacando asi la esencia de la comunidad. con lo que coinciden 
Galdo Y Gómez (1980). Por su parte Monteagudo (1980) afirma que la comunidad tendrá vigencia a mayor pobreza de las familias comuneras, con lo cual las tendencias a la pauperización campesina reforzarían los vínculos comunales.

Para Pásara (1972) las comunidades sufren un proceso de desestructuración. En la misma línea, la Confederación Nacional Agraria (CNA: 1974) propone que la concentración de recursos lleva a un deterioro de la comunidad, debilitando la reciprocidad de ese modo. Orlove (1979), por el contrario, afirma que las relaciones de parentesco y reciprocidad ayudan a mantener y aumentar la desigualdad no conservando, por consiguiente, a la comunidad, cuya organización favorecería a los ricos.

Por último, Plaza $(1981,1982)$ afirma que, pese a los cambios, la comunidad es una altemativa de producción y organización para los campesinos.

\section{Dinámica de la economía campesina.}

Las caracterizaciones de campesinos y economía campesina no dejan de estar acompañadas por discusiones sobre su "reacción", "papel", "persistencia" y/o "futuro" como producto del desarrollo capitalista. La mayor parte de autores señala que los campesinos subsisten en este tipo de formación social.

Para J. Golte (1981), el patrón andino enfrenta una nueva racionalidad -mercantil- pero subsiste por las condiciones de baja productividad de los recursos. El mismo autor presenta la organización andina como el conjunto socio-económico que articula producción de bienes de uso para el consumo directo con mercancías. En una perspectiva macro, Figueroa (1981) sostiene que ha habido un cambio en el papel de la economía campesina: de proveedora de alimentos a proveedora de fuerza de trabajo.

Caballero (1976), en base a una revisión estadística afirma que la reforma agraria interfiere poco con la economía campesina. Esto constituye una evidencia importante, agregada a las existentes, sobre el impacto reducido de este proceso en el minifundio. En un trabajo posterior (1983), afirma que la economía campesina es marginal al conjunto de la economía, discrepando con posiciones que la presentan como funcional en tanto abarata el costo de producción de la fuerza de trabajo (Aramburú 1979).

La idea del campesino como semi-proletario está presente en buena parte de trabajos. El argumento se sustenta en la importancia creciente del ingreso por venta de fuerza de trabajo en el ingreso campesino ${ }^{5}$-entre $250 / 0$ y $300 / 0--$, importancia que va asociada a las migraciones estacionales, que realizan los campesinos. Rivera (1982) asume que son parte de un proceso de descomposición de la economía campesina, mientras que para Vega (1976) se trata de una reproducción deteriorada frente a la penetración capitalista, lạ que además se acompaña de pauperización y desempleo. También Mariano 
Valderrama afirma que el parcelario minifundista es un semi-proletario ya que el uso intensivo de la tierra lo empobrece y genera la migración. Es Figueroa (1981) quien llega a la afirmación más audaz: la familia campesina es también proletaria.

Otra hipótesis importante es aquella que afirma que los campesinos persisten en un capitalismo no pleno que impide la proletarización completa (Campaña, Rivera: 1979), y que además para desarrollarse en el agro necesita de ellos, lo que se produce a través de las migraciones (Rivera 1982). Asimismo, una de las conclusiones del Seminario Problemática Agraria Peruana presenta dudas sobre la inminencia de la proletarización para los campesinos.

La pauperización, por factores endógenos como serian el incremento de población o el decremento en la calidad de los recursos es una idea recogida por Romero (1978).

Rodrigo Sánchez $(1979,1982)$ coincide en que la economía campesina subsiste en función de su relación con la sociedad global; para él, sin embargo, en base a la evidencia del valle del Mantaro, la tendencia es clara: la constitución de una pequeña burguesía por el ya desarrollo del intercambio mercantil simple y la proletarización o semi-proletarización. Además, afirma que la economia campesina no se adecúa frente al capitalismo en tanto no es un objeto.

En último lugar, quisiera presentar la hipótesis de Dancourt (1980) sobre los posibles impactos del desarrollo capitalista en áreas rurales. Este genera un conflicto entre la economía terrateniente y la economía campesina. El triunfo de la primera llevaría a su consolidación, mientras el triunfo de la segunda conduciría a su destrucción, en tanto aumentaría la presión por tierras. Estaríamos entonces frente a emergentes kulaks. Es esta segunda vía la que el autor demuestra en su trabajo.

De presentar la dinámica a un nivel de unidades familiares -economía campesina - trataré de ubicarla y presentarla en un contexto más amplio que es el de la comunidad.

\section{Diferenciación campesina, descampesinización.}

Desde que Lenin (1974) introdujera el término, es bastante lo que se ha discutido al respecto. Lenin presentó el problema desde lo que ocurría en la Rusia de principios de siglo, que vivia un proceso de desarrollo capitalista. Este penetraba a la economía campesina -concretamente las comunas campesinas rusas- destruyéndola a través de la concentración de recursos. Ello generaría un sector poseedor y otro sector desposeído, embriones de burguesía y proletariado agrícolas, además de ejército industrial de reserva, a través de la expulsión y migración de población. Es así que el proceso de diferenciación campesina es en última instancia --o en otras palabras un proceso de descampesinización. 
Las aproximaciones al problema en el Perú tienen como referente la presentación de Lenin, unos para tratar de "adecuarse" al modelo, y otros para refutarlo. Todos concuerdan, como es de esperar, en que la dinámica de la diferenciación debe remitirse a las relaciones con el desarrollo económico nacional.

Héctor Maletta (1978) es quien más cerca está de la posición de Lenin, sustentándola con un trabajo estadístico sobre los censos de 1940-19611972. Estima que el campesinado estaría compuesto por aproximadamente 900,000 personas, en el mejor de los casos. Además, su tendencia a la descomposición es clara, aun cuando lenta -dos o tres generaciones (1978 b)-, la que no se-vería obstaculizada ni por la comunidad ni por la hacienda. La misma existencia de reciprocidad es un índice de la predominancia de la economia familiar privada, en lo que coincidiría Orlove (1979). Sería entonces objetiva y fuerte la tendencia del Perú a no ser más un "país campesino".

Aramburú (1979) polemiza con Maletta. No cuestiona tanto sus cifras sobre población rural-urbana como sus interpretaciones. Este autor propone no una descomposición de la economia campesina pero sí una articulación entre esta y la economía capitalista. Esta se serviría de aquella en tanto abarata el costo de reproducción de la fuerza de trabajo. En otras palabras, el desarrollo capitalista no implicaría la destrucción de formas tradicionales de producción, o de las formas no capitalistas. Por otro lado, la descampesinización tiene como sustento el desarrollo de la contradicción necesidades de consumo crecientes de la unidad familiar versus términos de intercambio desfavorables, lo que se desprende de la función de la economía campesina de proveedora de bienes y servicios baratos. Sin embargo, la descampesinización no implica la inmediata proletarización.

Sobre la diferenciación, es posible distinguir claramente dos posiciones: la primera sostiene que la diferenciación es producto de fenómenos en el ámbito de la circulación, como serían las redes comerciales, los servicios, la educación, las relaciones con la "sociedad global"; la segunda sigue el enfoque clásico en tanto afírma que la diferenciación se está basando en el Perú en el desigual acceso a recursos y la consiguiente desigual explotación. Las comunidades serían escenario y protagonista de estos procesos.

La segunda posición es sostenida por menor número de autores: Pásara (1972) afirma que los ricos y pobres en las comunidades se encuentran en función del acceso a la posesión de tierras. Para los teóricos de la CNA (1974) se trataría del desigual acceso a recursos, lo cual se relaciona con la conducción indirecta. Orlove (1979) ampliaría el argumento al postular que los ricos tienen más interés en la tierra que los pobres, por cuanto tienen posibilidades alternativas de empleo fuera de las comunidades no peleando por consiguiente por sus tierras.

La primera posición es la más generalizada. Plaza (1981) señala que no es la acumulación de recursos la que genera la diferenciación sino su forma de inserción en los sectores de comercio, transporte y servicios. Caballero 
(1981) afirma que se trata de usar en provecho propio los vínculos mercantiles, mientras que Montoya (1980 a) coincide con Plaza, planteando sin embargo una disgregación importante: estaría ausente la determinación productiva en el proceso, por lo cual los "embriones de clase" en las comunidades adolecen de una condición histórica para su constitución en clases a plenitud.

Para economistas como Caballero 91981, 1983) y Gonzales (1978, s.p.d.i.) la diferenciación campesina pasa por la interiorización del mercado de trabajo en las comunidades, en tanto en pago a la fuerza de trabajo es parte de una contradicción interna. Para Caballero, habría una resistencia campesina a la proletarización. Gonzales, por su parte, agrega que la diferenciación parte de contradicciones internas y externas a los campesinos, además de identificarla con descampesinización. Para Cencira (1980), por el contrario, la diferenciación no es interna, además de no generar grupos con intereses opuestos.

Villasante (1978) coincide con Gonzales, señalando además que la dirección del proceso es función del desarrollo del capitalismo en la sociedad y especificamente en la agricultura.

Campaña y Rivera (1978), antropólogos, presentan una tesis que propone algunos elementos nuevos. Parten de que en nuestros países, el agro sirve para producir mano de obra barata para la extracción de materias primas de consumo externo. Es asi que la descampesinización habría estado determinada por este uso de mano de obra campesina parcialmente expulsada. Por su parte, la diferenciación estaría basada en la actividad de los campesinos como proletarios que se transforman en semi-proletarios, es decir en la experiencia salarial fuera de la comunidad. Además, (1979) la descampesinización es parcial: sólo una parte de la población campesina es expulsada. Estas reflexiones surgieron de estudios de los autores en el valle del Mantaro.

Caballero (1981) sostendría una tercera posición: el desarrollo capitalista genera fuerzas destructoras de la organización campesina a través de la introducción de nuevas mercancías, difusión del mercado y moneda, etc.; y fuerzas constructoras del capitalismo: capacidad de reproducir la mano de obra a través del salario y del capital para subordinar realmente al trabajo. Para el autor, predomina la primera: disociación de los trabajadores de sus medios de producción pero no su incorporación, o conversión, en proletarios.

\section{Notas finales.}

Estos temas han conocido un boom desde la década del 70 fruto de la problemática que el agro empezó a plantear con fuerza desde los 50 y de la reforma agraria implementada por el Cobierno Militar. Es mucho lo que se ha escrito al respecto. ¿Qué es lo que queda?

No hay consenso todavía sobre una conceptualización de campesinos y 
campesinado, en lo cual no estamos muy lejos de los principales teóricos extranjeros. Hay más coincidencia de opiniones respecto al impulso mercantil que sustenta la diferenciación campesina, a diferencia de los casos "clásicos".

La inminencia o no de la proletarización es algo discutido. La semi-proletarización es una idea que es encontrada en casi todos los autores, aun cuando podamos discutir sobre la pertinencia de una categoría como esa.

Pienso, en coincidencia con algunos de los autores presentados, que el proceso de desarrollo del capitalismo encuentra obstáculos en la economía campesina, debido a la baja productividad de los recursos, y a un apego por la tierra, lo que es traducible por resistencia a la proletarización. Además, como campesinos además de proveer alimentos, of recen fuerza de trabajo estacionalmente. Sigo a los clásicos en cuanto a que son condiciones de explotación de la fuerza de trabajo en el proceso productivo las que serían causa y definirán el proceso de descampesinización. Dominar el comercio y los servicios no es concomitante a esta explotación, sino del dominio de la circulación que no afecta directamente las características del ámbito de la producción que definen al campesino- .

Considero, por otro lado, que la hipótesis de Monteagudo (1981) sobre la vigencia de la comunidad a mayor pobreza de los recursos familiares tiene un gran poder explicativo, además de reflejar una tendencia que considero más real. La organización comunal no tiene vida per se, se sustenta en condiciones materiales objetivas que son las que le dan vitalidad.

La discusión que ha sido reseñada da cuenta de una parte de la problemática del sector más pobre y olvidado, o bien tristemente recordado - Uchuraccay es un ejemplo- de la población peruana. Es necesario tener presente que este sector está en la base de la pirámide de ingresos, característica que los hace necesarios protagonistas de un esfuerzo político serio por mejorar sus condiciones de vida. Por este motivo, resulta pertinente tratar de evaluar su dinámica frente a la dinámica capitalista que vive el país, como forma de conocer mejor cuáles elementos serían los que más eficazmente mejorarían su situación. 


\section{NOTAS}

1 Rochabrun al plantear este término, "quiere denotar una perspectiva, no una definición" (pág. 7). La explicación queda en las propias palabras del autor: “. . . la historia del país en el siglo XX atestigua una emergencia y desarrollo de las determinaciones capitalistas pero bajo una forma parcial, incompleta en sus distintas manifestaciones. Cada determinación está presente, por lo general, a través de fenómenos superficiales y fragmentarios que dan la impresión de una existencia profunda y plena de las mismas. Mientras que en el capitalismo originario cada determinación posee una fuerza totalizadora que la suelda unitariamente con todas las demás, en el capitalismo sub-determinado encontramos que esas determinaciones no reconstruyen la misma organicidad, conducen a otra organicidad" (Loc. cit.).

2 Sobre la importancia cuantitativa de esta oferta y sobre el problema de precios y términos de intercambio campociudad se están llevando adelante investigaciones por parte de egresados de Economía de la PUC.
3 La expresión extrema, y sentidamente actual, de estas posiciones podría ser encontrada en el Partido Comunista del Perú -"Sendero Luminoso"- y la "guerra popular y prolongada del campo a la ciudad".

4 Sobre estos términos todavía hay un debate internacional (revisar, por ejemplo, Archetti, Stolen "Explotación familiar y acumulación de capital en el campo argentino", Buenos Aires, Siglo XXI, 1975, cap. II). Presento los tres siguiendo los apuntes de clase del curso "Problemas Rurales" dictado por Orlando Plaza y Pedro Gibaja -P.A. de Ciencias Sociales, Puc, semestre 83-I-: campesinos haría referencia a la unidad familiar; campesinado a la clase social, y economía campesina a la racionalidad y organización productiva de sectores donde las nociones de salario y ganancia monetarias no están presentes.

5 Ya han surgido cuestionamientos a la propucsta de que esta fuente de ingreso constituya efectivamente ingreso campesino.

\section{BIBLIOGRAFIA}

\section{ALBERTI, Giorgio y Enrique MAYER}

1974 Reciprocidad e intercambio en los Andes peruanos, Lima, IEP.

AR AMBURU, Carlos Eduardo

1979

"El Campesinado peruano. Crítica a H. Maletta", en Análisis, No. 8--9, Lima. 
1983 "Acumulación Capitalista y migración en la población rural: perspectivas para la investigación" en J. Iguiñiz ed., La Cuestión Rural en el Perú, Lima, Puc.

s/f "Campesinado y desarrollo regional", Lima, Puc, mimeo.

BR ACCO, Mercedes

1980 Migración eventual a la Ceja de Selva: un caso de semiproletarización rurul, Lima, Puc, memoria de bachillerato.

BRADBY, Bárbara

1975 La destrucción de la economia natural en el Perú. Un problema de articulación de modos de producción, Lima, Puc, Mimeo.

CABALLER(), José María

1976 Reforma y Reestructuración Agraria en el Perú, Lima, Puc, mimeo.

1979 La situación del campesinado andino y las decisiones de política económica, Lima, Puc, mimco.

1981 Economía agraria de la sierra peruana, Lima, IEP.

1983 "Agricultura peruana: conomía política y campesinado. Balance la investigación recicnte y patrón de evolución" en J. Iguiñiz ed., La cuestión rural en el Perú, Lima, Puc.

CABALLERO, José María y Elena ALVAREZZ

1980 Aspectos Cuantitativos de la reforma agraria, Lima, IEP.

CADENA, Ma. Soledad de la

1980 Economía campesina: familia y comunidad en Yauyos, Lima, Puc, tesis.

CAMPAÑA, Pilar y Rigoberto RIVERA

1978 "El proceso de descampesinización en la sierra central del Perú" en Estudios Rurales I.atinoamericanos, Vol. 1, No. 2, Bogotá.

1979 "Campesinado y Migración en una sociedad de enclave", en Debates en Antropología, No. 4, Lima.

CLAVERIAS, Ricardo

1976 El impacto diferencial de la reforma agraria y las tendencias en la estructura económica de las comunidades campesinas, Puno, Idisa, mimeo.

CENCIRA

1977 Comunidades campesinas. Proceso histórico do diferenciación regional, Lima. 
CONFEDERACION NACIONAL AGRARIA

1974 "Reestructuración de la comunidad campesina", Lima, mimeo.

DANCOURT, Oscar

1980 Aspectos económicos de las luchas campesinas, Lima, Puc, mimeo.

DOBYNS, Henry

1972

Comunidades campesinas del Perú, Lina, Editorial de Estudios Andinos.

EC:UREN, Fernando

1982

Situación actual y perspectivas del problema agrario en el Perú, Lima, Desco.

FIGUEROA, Adolfo

1981 La economía campesina de la sierra del Perú, Lima, Puc.

1982 "Recstructuración agraria en la sicrra peruana", en Eguren ed., Situación actual y perspectivas del problema agrario en el Perú, Lima, Desco.

1983 "Mito y realidad de la cconomía campesina en el Perú", en J. Iguiñiz ed., La cuestión rural en el Perú, Lima, Puc.

FONSEC.A, César

1973

Sistemas económicos andinos, Biblioteca Andina, Lima, Universidad de San Marcos.

\section{(; ALD(), Raúl y Jorge Alberto G(OMEZ}

1980 Formas tradicionales de trabajo campesino en los Andes, Lima, OIT.

G(OLTE, Jurgen

1980 La racionalidad de la Organización andina, Lima, IEP.

GONZALES, Efrain

1978

"Comunidades campesinas y diferenciación campesina" en Crítica Andina, No. 2, Cusco.

1980

"Economia Familiar Comuncra", en Economía, Vol. 3, No. 5, Lima.

1983

“ ¿Problema de empleo o de reproducción de la fucrza de trabajo?". en Revista Andina, Vol. 1, No. 1, Cusco.

HANDELMAN, Howard

Lucha campesina en los Andes, Lima, Puc, mimeo. 
IC:UINIZ, Javier

1983

La cuestión nural en el lic ni, Lima, Puc.

LENIN, Vladinir

1975 l:l desarrullo del capisalismo c'n Rusia, Barcelona. Ariel.

MAI)UEÑ(), Patricia

1981

lineria de trabajo en la econumia campesina. I:l caso de la comnnidad de Chura, pronincia de Canchis, Cusco, Lima, Puc, memoria de bachiller.

MALE:TTA, Héctor 1978

"Perú, epais campesino? Aspectos cuantitativos de su mundo rural". con Análisis No. 6, Lima.

1979a "Campesinado, precio y salario". en Apuntes No. 9, Lima.

$1979 b$ "Formas de suburdinación del trabajo al capital". en Crítica Andina No. 4, Cusco.

1979c "El discreto encanto del campesinado. Réplica a Aramburú". en Análisis No. 8.9, Lima.

MAKX, Carlos

1981

El Capital, Madrid, Siglo XXI.

MINISTERI() DE ACRICULTURA

1980 Comunidades campesinus. Información Bd́sica, Lima.

M()N'TEAGUIX), Ma. Cristina

1981

liconomia familiar y comunal campesina: el caso de las comunidades campesinas de Paruro, Cusco, Lima, Puc, memoria de bachiller.

M()NT()Y A, Rodrigo

$1980 a$

" A dónde va el campo andino?". en Socicdad y Política, No. 8. Lima.

$1980 b$ "Comunidades campesinas: historia y clase". en Sociedad y Pulitica, No. 9, Lima.

ORLOVE, Benjamín

1979

"Ricos y pobres. Desigualdad en las comunidades campesinas", en Estudios Andinos, No. 15, Lima.

PASARA, Luis

1972

¿Qué hacer con la corrunidad campesina?, Lima, Cencira, mimeo. 
PLAZA, Orlando

1980

"La problemática de la comunidad campesina" en Realidad del campo peruano después de la reforma agraria, Lima, Cic.

1982

"Vigencia de las comunidades campesinas" en F. Eguren ed., Situación actual y perspectivas del problema agrario en el Perú, Lima, Desco.

RIVERA, Rigoberto

1982

"El papel del campesinado en la expansión del capital en el sector rural" en Estudios Rurales Latinoamericanos, Vol. 5, No. 3, Bogotá.

R()CHABRUN, Guillermo

1977 "Apuntes para la comprensión del capitalismo en el Perú" en Análisis, No. 1, Lima.

ROJAS MESTRE, Carmen

1977

Capitalismo y revitalización en la comunidad campesina de Matachico, Lima, Una, mimeo.

ROMERO, Lilia

1978

Introducción al estudio de la reforma agraria, la economía campesina y la diferenciación campesina en el Perú, Lima, Ministerio de Agricultura, mimeo.

SANCHEZ, Rodrigo

1980 Capitalismo y persistencia del campesinado parcelario: el caso de la sierra central, Lima. UNA, mimeo.

1982

"La teoría de 'lo andino' y el campesinado de hoy", en Allpanchis

No. 20, vol. XVII, Cusco.

SEMINARIO PR()BLEMATICA AGRARIA PERUANA

1977 a Chupaca, Huancayo, Junín.

1977 b Huamanga. Ayacucho.

VALDERRAMA Mariano

1977 "El proceso de fragmentación de la propiedad rural en el departamento de Cajamarca". en Debates en Sociología, No. 1, Lima.

VEGA, Ma. Gabricla

1976

"Economía campesina y capitalismo en el Perú" en Campesinado y capitalismo ell el Perú, Aproximaciones a partir de la crítica de la economía política. Lima. Puc, Mimeo. 
VILLASANTE, Marco

1978

"El problema mercantil simple y la economía campesina de Espinar" en Crítica Andina, No. 1. Cusco.

1979

"Ecunomia y diferenciación campcsina en las provincias altas, el caso de Espinar", en Crítica Andina, No. 3, Cusco. 